\title{
Eradication of the mongoose is crucial for the conservation of three endemic bird species in Yambaru, Okinawa Island, Japan
}

\author{
Tsutomu Yagihashi $(\mathbb{D} \cdot$ Shin-Ichi Seki $\mathbb{D} \cdot$ Tomoki Nakaya (D) Katsushi Nakata • \\ Nobuhiko Kotaka $(1)$
}

Received: 4 September 2020/ Accepted: 20 March 2021 / Published online: 12 April 2021

(C) The Author(s) 2021

\begin{abstract}
Okinawa Island, Japan, is a globally important biodiversity hotspot. Three endemic bird species, Okinawa rail (Hypotaenidia okinawae), Okinawa woodpecker (Dendrocopos noguchii), and Okinawa robin (Larvivora namiyei), are found only in the Yambaru region of the northern part of Okinawa Island. In order to conserve endemic species, it is important to determine the effect of alien species on endemic species. We conducted playback surveys four times every three years from 2007 to 2016 to evaluate the recent distribution of these three forest-dwelling bird species during the breeding season. Then, the association between the numbers of detections of these three species with the invasive mongoose density and the hardwood forest area was evaluated with a generalized additive mixed model (GAMM). The
\end{abstract}

Tsutomu Yagihashi and Nobuhiko Kotaka have contributed equally to the study

T. Yagihashi $(\bowtie)$

Department of Forest Vegetation, Forestry and Forest Products Research Institute, 1 Matsunosato, Tsukuba, Ibaraki 305-8687, Japan

e-mail: yagihasi@affrc.go.jp

\section{S.-I. Seki}

Kansai Research Center, Forestry and Forest Products

Research Institute, Kyoto, Kyoto 612-0855, Japan

T. Nakaya

Graduate School of Environmental Studies, Tohoku

University, Sendai, Miyagi 980-0845, Japan results showed that the distribution areas of these bird species have been recovering since the 2007 within the small Indian mongoose (Urva auropunctata) controlled area. The GAMM results showed that these bird species were abundant in areas with fewer small Indian mongooses and larger areas of hardwood forests. Thus, the mongoose had a negative impact not only on the flightless rails but also on the woodpeckers and the robins. In recent years, most of the old-growth forests have been designated as protected forests, and large-scale logging is no longer taking place in Yambaru. Eradication of the mongoose is particularly important for the conservation of these three endemic bird species.

Keywords Avian conservation - Flightless bird . Invasive species · Forest area

K. Nakata

Yambaru Wildlife Conservation Center, Kunigami, Okinawa 905-1413, Japan

N. Kotaka $(\square)$

Kyushu Research Center, Forestry and Forest Products Research Institute, Kumamoto, Kumamoto 860-0862, Japan 


\section{Introduction}

Endemic species on islands are generally vulnerable to foreign predators (Courchamp et al. 2003). In order to conserve endemic species, it is important to clarify the effect of alien species on endemic species. Three endemic bird species, Okinawa rail (Hypotaenidia okinawae), Okinawa woodpecker (Dendrocopos noguchii, Syn. Sapheopipo noguchii), and Okinawa robin (Larvivora namiyei, Syn. Luscinia komadori namiyei), inhabit Okinawa Island, Japan, a globally important biodiversity hotspot. Currently, the breeding distributions of these species are limited to the Yambaru region in the northern part of Okinawa Island.

Okinawa rail is a flightless forest rail that was discovered in 1981 (Yamashina and Mano 1981). When the species was discovered, its distribution had already been limited to Yambaru, and in 2005, it was almost limited to Kunigami Village in the northernmost part of Yambaru (Ozaki 2014). Okinawa woodpecker is a medium-sized woodpecker. It is thought to have been found in the northern half of Okinawa Island at the beginning of the twentieth century (Kotaka 2014). In the 1970s, its distribution was restricted to mature forests around several mountains in Yambaru (Ogasawara and Ikehara 1977; Short 1973). Okinawa robin is a small-sized passerine. It was widely distributed in Okinawa Island in 1904 (Ogawa 1905), but in 1980, its distribution was limited to the central and northern part of the island, and in the 2000s, its distribution was limited to the northern part of the island (Seki 2014). In the IUCN Red List of Threatened Species, Okinawa rail is categorized as "Endangered" (BirdLife International 2016), Okinawa woodpecker as "Critically Endangered"(BirdLife International 2018), and Okinawa robin as "Near Threatened" (BirdLife International 2017). In the latest Red List of the Ministry of the Environment of Japan, the rail and the woodpecker are categorized as "Critically Endangered", and the robin is categorized as "Endangered" (Ministry of the Environment Government of Japan 2019).

Introduction of mammalian carnivores may have a significant impact on the distribution of these three bird species. There used to be no mammalian carnivores in Okinawa Island. It is considered that these three endemic bird species have not evolved to adapt to predation by mammalian carnivores. The small
Indian mongoose (Urva auropunctata, Syn. Herpestes auropunctatus) was introduced in the southern part of Okinawa Island in 1910 (Kishida 1931). The small Indian mongoose is named in the IUCN list of 100 of the World's Worst Invasive Alien Species (Lowe et al. 2000). It has expanded its distribution in many regions where it has introduced, such as the Hawaiian Islands (Baldwin et al. 1952), the West Indies (Horst et al. 2001), Mauritius (Roy and Harris 2002), the Adriatic Islands (Barun et al. 2010), and the Ryukyu islands (Mizuta et al. 2017; Watari et al. 2007; Yamada and Sugimura 2004), causing extinction or decline of endemic species (Barun et al. 2011). After its introduction to Okinawa Island, the mongoose spread north and reached southern Yambaru in the 1990s (Abe 1994; Yamada and Sugimura 2004). Ozaki et al. (2002) reported a reduction in the area of distribution of Okinawa rail following the invasion of the mongoose in Yambaru. The extent to which the mongoose influences the distribution of Okinawa woodpecker is unknown, but predation of the woodpecker by the mongoose has been confirmed (Kotaka 2014). Moreover, Okinawa robin may be vulnerable to the mongoose because they sometimes feed on or nest near the ground (Kotaka et al. 2009; Seki 2014), although there is a belief that the robin are not susceptible to the mongoose (BirdLife International 2017). Therefore, it is necessary to investigate how the mongoose affects these three species. However, as far as we know, there have been few statistical analyses of the extent to which the mongoose influences the distribution of these species, except in the case of the rail (Ozaki 2010).

The Okinawa Prefectural Government and the Ministry of the Environment of Japan launched a mongoose removal project (2000-2004) in Yambaru. Pursuant to the Invasive Alien Species Act enacted in 2005, a control plan was developed and control programs were implemented (Ministry of the Environment, Okinawa Prefecture 2019). In 2005 and 2006, mongoose control fences were constructed in the southern part of Yambaru. The mongoose controlled area (ca. $280 \mathrm{~km}^{2}$ ) was separated from the unmanaged areas by the fence and open water. Livetraps have been used to control the mongoose, and kill traps with bird-excluding guard have also been used since 2008. The current goal is to completely eradicate the mongoose from the controlled area by the end of March 2027. Intensive capture operations and other 
measures have markedly reduced the mongoose populations and densities, as well as their distribution ranges in Yambaru (Ministry of the Environment, Okinawa Prefecture 2019). This mongoose control program may have a positive effect on the distribution of these three bird species. Therefore, it is necessary to clarify whether the distribution areas of these three bird species are recovering after the start of the control programs.

Because these three bird species are forest-dwelling, it is important to consider not only the effects of mongoose, but also the effects of the forest environment. It has been reported that mature forests over 40 years old are necessary for these three bird species to inhabit (Department of Environmental Affairs, Okinawa Prefecture 1993). Logging peaked from the mid-1920s through the 1950s in Kunigami village in Yambaru (Saito 2011). The area of mature forests was reduced to several square kilometers in Yambaru in the late 1970s (Ogasawara and Ikehara 1977). With the increasing awareness of environmental protection and the declining demand for timber, the logging area in Yambaru has rapidly decreased (Department of Agriculture, Forestry and Fisheries 2019). In 2008, 84\% of the forests in Yambaru were over 40 years old (Department of Agriculture, Forestry and Fisheries 2019). Therefore, we considered that the forest had recovered sufficiently in 2007 when we started this study. Then, we focused on the impact of the mongoose and only verified the effect of forest area for considering the effect of forest environment.

To determine the recent distribution of the three bird species, we conducted playback surveys four times every 3 years from 2007 to 2016. To evaluate whether the distribution areas of these species are recovering, we assessed changes in the number of sites where each species was detected. To determine the effects of the alien mongoose and the amount of forest area on these species, we carried out statistical analysis with a generalized additive mixed model (GAMM).

\section{Methods}

Study area

The survey was conducted in the Yambaru region of northern Okinawa Island, Ryukyu archipelago, Japan.
Yambaru originally meant a large mountainous area, but in recent years it has often referred to the three villages of Kunigami, Higashi, and Ogimi (Fig. 1). Here, Yambaru has been defined as the combined area of the three villages (ca. $340 \mathrm{~km}^{2}$ ). There are two mongoose control fences in Yambaru; the mongoosecontrolled area is north of the two fences and the area between the two fences is called the buffer area (Figs. 1, 2). About half $\left(173 \mathrm{~km}^{2}\right)$ of Yambaru was designated as Yambaru National Park in 2016. In 2019, the Japanese government submitted a nomination dossier to UNESCO for four regions of the Ryukyu archipelago, including Yambaru, for registration as a World Natural Heritage Site. Yambaru is located in a humid subtropical climatic zone, with an average annual temperature of $20.7^{\circ} \mathrm{C}$ and an average annual rainfall of $2501 \mathrm{~mm}$ at $\mathrm{Oku}$, Kunigami Village, $232 \mathrm{~m}$ above sea level (Japan Meteorological Agency, 2020). There are many natural and secondary evergreen hardwood forests dominated by Castanopsis sieboldii.

\section{Bird survey}

The survey was conducted during four breeding seasons: from April 10 to June 21 in 2007, from March 16 to June 16 in 2010, from March 13 to June 24 in 2013, and from April 18 to June 4 in 2016. The breeding season for the three species is spring. Although the breeding season fluctuates from year to year due to climatic factors, we observed that at least some individuals of all three species were incubating or feeding their chicks during the study period. We prepared 281 survey points, each set on a $30^{\prime} \mathrm{N} \times 45^{\prime}$ E Standard Area Grid (Tokyo Datum) (Japan Map Centre 1998), except for some places that were difficult to visit or were in restricted areas, such as the United States Marine Corps training area (Mongoose control programs have also been carried out in the United States Marine Corps training area with special permission). Of the 281 points, we were able to survey 269 points in 2007, 269 in 2010, 264 in 2013, and 277 in 2016. We used a playback method for the survey to increase the detection rate (Bibby et al. 2000). The survey was conducted by four to six persons in each survey year. One of them participated in all four surveys for supervision. Investigators with sufficient experience in bird detection surveys were selected and pre-survey training was conducted in 
Fig. 1 Map of the study area in Yambaru, Okinawa Island, Japan. The map was generated by using software R 4.0.2 and QGIS 3.12

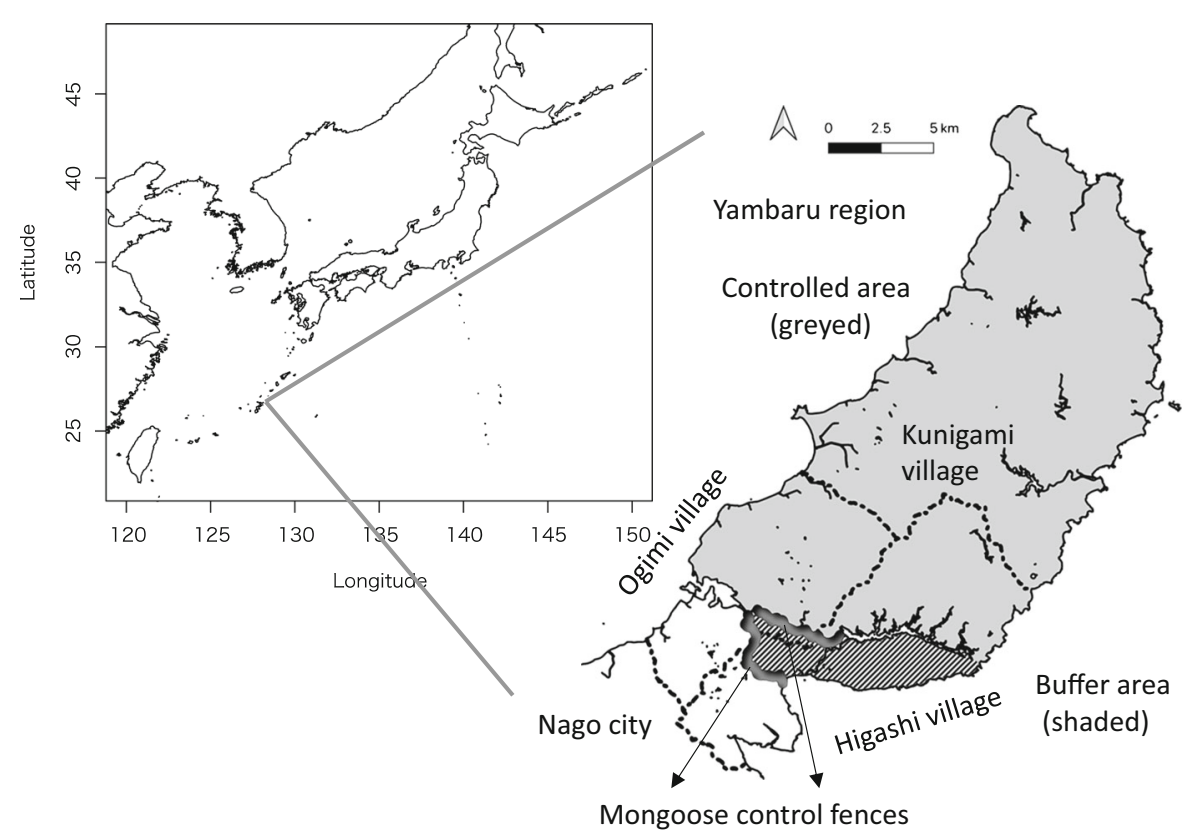

Japan) with a sampling rate of $48 \mathrm{kHz}$. We played the 2-min audio file five times at each sampling point, with a digital audio player (Apple, iPod, USA) and a loudspeaker (Toshiba, BK-701, Japan) at a sound pressure of approximately $90 \mathrm{~dB}$ at $1 \mathrm{~m}$ in front of the speaker. The 2-min audio file consisted of $20 \mathrm{~s}$ of Okinawa robin song, $10 \mathrm{~s}$ of silence, $10 \mathrm{~s}$ of Okinawa woodpecker drumming, $20 \mathrm{~s}$ of Okinawa woodpecker calls, $20 \mathrm{~s}$ of Okinawa rail territorial calls, and $40 \mathrm{~s}$ of silence. The broadcast was directed to the north, east, south, and west, in that order, and the last one was directed in a direction where the number of detections could not be determined in the first round. The number of individuals directly observed and the number of individuals whose sounds were detected were recorded. The direction and estimated distance were also recorded for each individual. To avoid duplicate counts, the direction and distance of each individual and the movement of each individual were used as a reference; for example, a voice heard from the same direction and at the same distance is considered to be the same individual. We assessed changes in the number of points where each bird species was detected, using the 244 points that could be surveyed in all observation years, to determine the area of habitat of each bird species. We counted the number of individuals of each bird species at each playback 
survey point (hereafter PSP) to determine the density of each bird species.

\section{Statistical analysis}

Considering possible nonlinear relationships between the response variable and explanatory variables, we used a generalized additive mixed effect model (GAMM) with the package gamlss (Rigby and Stasinopoulos 2005) on R 4.0.2 (R Core Team 2020). We also employed the $R$ package gamlss.spatial (Bastiani et al. 2018) to include a spatially structured random effect in the GAMMs to account for unobserved spatially correlated factors. In the model, the detected number of individuals of each bird species at each PSP was the response variable, and three factors - the smooth terms of catch per unit effort (CPUE) (catches/100trap-days) of small Indian mongoose in the year before the playback survey, the area of hardwood forest within a radius of $300 \mathrm{~m}$ around each PSP, and the survey time dummies (The dummy variable of kth survey takes the value of 1 in case that the observation was obtained in the survey and 0 otherwise) - were the explanatory variables. We used a radius of $300 \mathrm{~m}$ for all species, because most birds were detected within $300 \mathrm{~m}$ of the PSP. Because the breeding seasons of these three species are in the spring, the CPUE of the year before the playback survey was used for the analysis. Because the CPUE is a highly skewed distribution, when the model is applied there are few observations of high values, and the estimates of results become unstable. Therefore, we applied a square-root transformation to mitigate the skewness of the variable. We considered the CPUE of small Indian mongoose as a measure of the density of the mongoose (Fig. 3a) and the area of hardwood forest as the amount of habitat suitable for forestdwelling birds. Detections of each bird species were modelled assuming Poisson distributed errors and a $\log$ link function. The spatially structured random effect was specified by the Gaussian intrinsic autoregressive model which makes the estimated values of the term closer among neighboring grids sharing borders (See Bastiani et al. (2018) for the details of the model). Generalized (Pseudo) $\mathrm{R}^{2}$ for the models was calculated by the Rsq function in the gamlss package (Nagelkerke 1991). Original vegetation data were obtained from the latest vegetation surveys of the National Survey on the Natural Environment conducted by Ministry of the Environment of Japan (Biodiversity Center of Japan 2020). QGIS 3.12 software (QGIS Development Team 2020) was used to calculate the area of hardwood forest within a radius of $300 \mathrm{~m}$ around each PSP. Data on the CPUE of small Indian mongoose were provided by the Ministry of the Environment of Japan and Okinawa Prefectural Government for research purposes only.

\section{Results}

Changes in the distribution areas of the three bird species

There has been an increasing trend in the number of detection points for all three species since 2007 (Table 1). In 2007, the distribution of Okinawa rail was mostly limited to Kunigami village, but since 2010 the number of detection points has increased not only in Kunigami village but also in Higashi village (Figs. 1 and 3b). However, the distribution of the rail was still limited to the mongoose controlled area (Fig. 3b).

Okinawa woodpecker was distributed in the mongoose controlled area and the buffer area, although the number of detection points in 2007 was small (Table 1, Fig. 3c). Since 2010, the number of detection points has increased (Table 1), and in 2013 and 2016, the woodpecker was also detected at a PSP in Nago City adjacent to Yambaru, although in only one location. (Figs. 1 and 3c).

The number of detection points of Okinawa robin at each PSP increased in 2016 compared with 2007 (Table 1), but its distribution was still limited to the mongoose controlled area and the buffer area (Figs. 1 and $3 \mathrm{~d})$.

Density of each bird species and its relation to mongoose density and forest area

The detected number of individuals of Okinawa rail at each PSP increased significantly in 2013 and 2016 compared with 2007 (Table 2). The detected number of Okinawa woodpecker at each PSP increased significantly in 2010 and 2013 compared with 2007, but the detected number in 2016 was not significantly different from that in 2007 (Table 3). For Okinawa 


\section{(a) CPUE of Urva auropunctata}

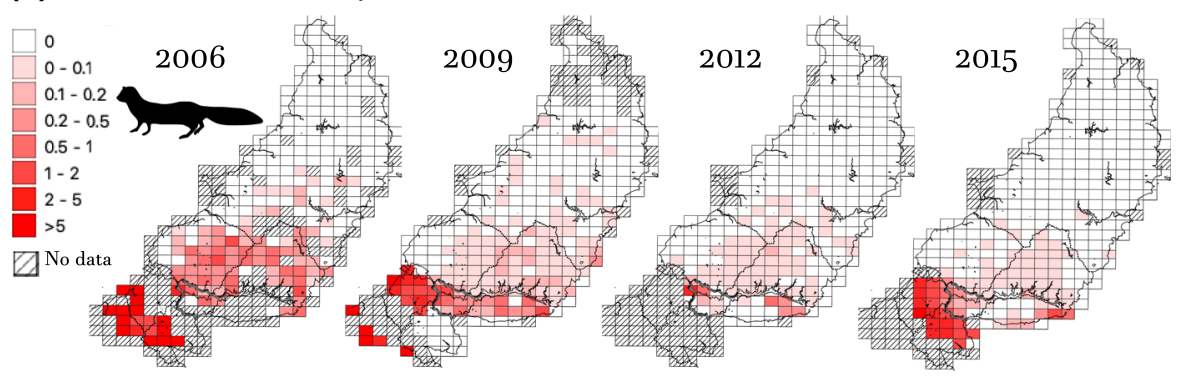

(b) Numbers of Hypotaenidia okinawae

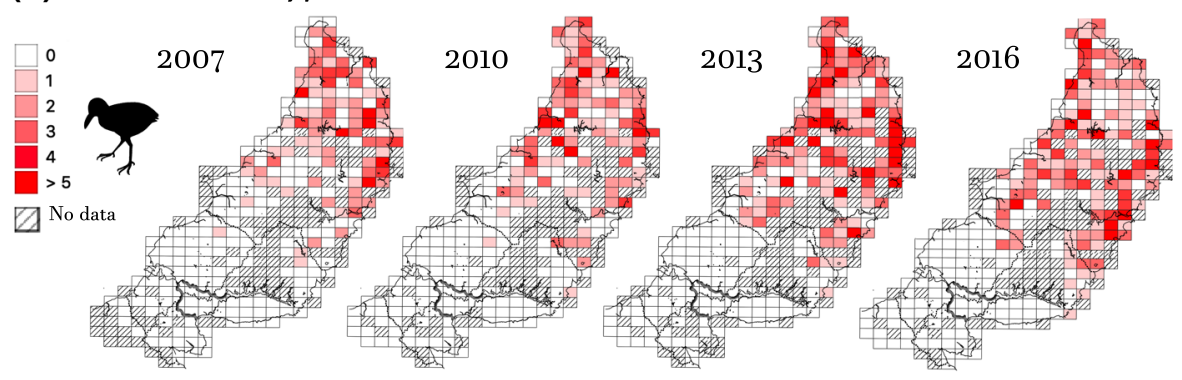

(c) Numbers of Dendrocopos noguchii

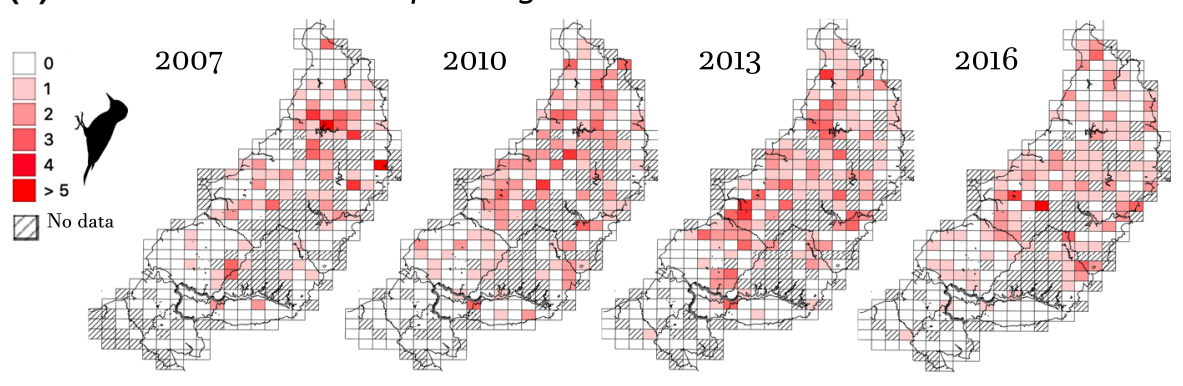

(d) Numbers of Larvivora namiyei

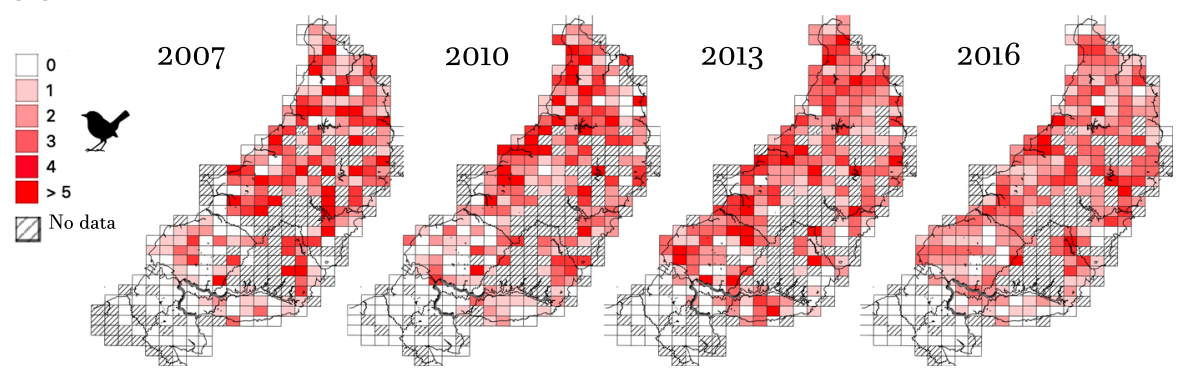

Fig. 3 a Catch per unit effort (CPUE) (catches/100 trap-days) of small Indian mongoose (Urva auropunctata) in the year before the playback survey shown in the Standard Area Grids. b Numbers of Okinawa rails (Hypotaenidia okinawae) detected at each playback survey point shown in the Standard Area Grids. c Numbers of Okinawa woodpeckers (Dendrocopos noguchii) detected at each playback survey point shown in the Standard Area Grids. d Numbers of Okinawa robins (Larvivora namiyei) detected at each playback survey point shown in the Standard Area Grids. The number in the upper left of the map indicates the calendar year 
Table 1 Number (percent) of points where each bird species was detected, based on the 244 points that could be surveyed in all observation years

\begin{tabular}{lcccc}
\hline Species & 2007 & 2010 & 2013 & 2016 \\
\hline Hypotaenidia okinawae & $79(32.4)$ & $89(36.5)$ & $109(44.7)$ & $112(45.9)$ \\
Dendrocopos noguchii & $67(27.5)$ & $96(39.3)$ & $104(42.6)$ & $100(41.0)$ \\
Larvivora namiyei & $153(62.7)$ & $171(70.1)$ & $186(76.2)$ & $184(75.4)$ \\
\hline
\end{tabular}

robin, there were no significant differences between survey years (Table 4).

The detected number of the rail at each PSP was inversely proportional to the CPUE of the mongoose (Fig. 4a) and was directly proportional to the hardwood forest area (Fig. 4b). The partial effect size of the mongoose was greater than that of the hardwood forest area (Fig. 4a and b).

The detected number of the woodpecker at each PSP was inversely proportional to the CPUE of the mongoose (Fig. 4c). The relationship between the detected number of the woodpecker at each PSP and the hardwood forest area was nonlinear, but basically, the number of detections increased as the hardwood forest area increased (Fig. 4d). The partial effect size of the mongoose was greater than that of the hardwood forest area (Fig. 4c and d).

The relationship between the detected number of the robin at each PSP and the CPUE of the mongoose was nonlinear, but basically, the number of detections decreased as the CPUE of the mongoose increased
(Fig. 4e). The detected number of the robin at each PSP was proportional to the hardwood forest area (Fig. 4f). The partial effect size of the mongoose was greater than that of the hardwood forest area (Fig. 4e and $f$ ).

The negative effect of the mongoose was the largest for the rail (Fig. 4a, c, e).

\section{Discussion}

Negative impact of alien small Indian mongoose

The results of this study revealed the negative effect of small Indian mongoose on all three endemic bird species. All three species were less common in areas with more mongoose, suggesting that they are preyed upon by the mongoose. However, the extent of predation differed among species. Okinawa rail was the most strongly affected by the mongoose among the three species. This may be because the rail is flightless,

Table 2 Parameter estimates of generalized additive mixed model (GAMM) for the number of the Hypotaenidia okinawae at each playback survey point

\begin{tabular}{lllll}
\hline Variable & Estimate & s.e. & $t$ & $p$ \\
\hline (Intercept) & -0.3427 & 0.0889 & -3.8540 & 0.0001 \\
$p b$ (Mongoose, $d f=2.000001)$ & -1.9080 & 0.5599 & -3.4080 & 0.0007 \\
$p b$ (Hardwood Area, $d f=2.002857)$ & $1.42 \mathrm{E}-06$ & $3.50 \mathrm{E}-07$ & 4.0510 & 0.0001 \\
Year 2010 & 0.1064 & 0.1096 & 0.9700 & 0.3319 \\
Year 2013 & 0.6358 & 0.0932 & 6.8210 & $<0.0001$ \\
Year 2016 & 0.4454 & 0.0956 & 4.6580 & $<0.0001$ \\
No. of observations in the fit & 898 & & & $* * *$ \\
Residual degree of freedom & 763.46 & & & \\
Generalized (Pseudo) $\mathrm{R}^{2}$ & 0.7896 & & & \\
\hline
\end{tabular}

$p b$ represents the smooth term of GAMM, and $d f$ denotes the effective degrees of freedom fitted by the $p b()$. The estimated coefficient of the smoothing term and its standard error (s.e.) refer only to the linear component of the term

Significance codes: $* * * p \leq 0.001$ 
Table 3 Parameter estimates of GAMM for the number of the Dendrocopos noguchii at each playback survey point

\begin{tabular}{lllll}
\hline Variable & Estimate & s.e. & $t$ & $p$ \\
\hline (Intercept) & -1.0270 & 0.1235 & -8.3180 & $<0.0001$ \\
$p b$ (Mongoose, $d f=2.000005)$ & -1.0350 & 0.2993 & -3.4590 & 0.0006 \\
$p b$ (Hardwood Area, $d f=3.511147)$ & 0.0000 & $4.83 \mathrm{E}-07$ & 7.7230 & $<0.0001$ \\
Year 2010 & 0.2894 & 0.1240 & 2.3340 & 0.0198 \\
Year 2013 & 0.3204 & 0.1205 & 2.6580 & 0.0080 \\
Year 2016 & 0.0789 & 0.1257 & 0.6270 & 0.5306 \\
No. of observations in the fit & 898 & & & $* *$ \\
Residual degree of freedom & 771.80 & & & \\
Generalized (Pseudo) $\mathrm{R}^{2}$ & 0.4873 & & &
\end{tabular}

$p b$ represents the smooth term of GAMM, and $d f$ denotes the effective degrees of freedom fitted by the $p b()$. The estimated coefficient of the smoothing term and its standard error (s.e.) refer only to the linear component of the term

Significance codes: $* * * p \leq 0.001, * * p \leq 0.01, * p \leq 0.05$

Table 4 Parameter estimates of GAMM for the number of the Larvivora namiyei at each playback survey point

\begin{tabular}{lllll}
\hline Variable & Estimate & s.e. & $t$ & $p$ \\
\hline (Intercept) & 0.5378 & 0.0684 & 7.8660 & $<0.0001$ \\
$p b$ (Mongoose, $d f=3.455654)$ & -0.7665 & 0.1446 & -5.3000 & $<0.0001$ \\
$p b$ (Hardwood Area, $d f=2.004042)$ & $1.88 \mathrm{E}-06$ & $2.60 \mathrm{E}-07$ & 7.2230 & $<0.0001$ \\
Year 2010 & -0.0095 & 0.0867 & -0.1100 & 0.9130 \\
Year 2013 & 0.0871 & 0.0713 & 1.2220 & 0.2220 \\
Year 2016 & -0.0587 & 0.0730 & -0.8050 & 0.4210 \\
No. of observations in the fit & 898 & & & \\
Residual degree of freedom & 782.42 & & & \\
Generalized (Pseudo) $\mathrm{R}^{2}$ & 0.4916 & & & \\
\hline
\end{tabular}

Significance codes: $* * * p \leq 0.001$

$p b$ represents the smooth term of GAMM, and $d f$ denotes the effective degrees of freedom fitted by the $p b()$. The estimated coefficient of the smoothing term and its standard error (s.e.) refer only to the linear component of the term

terrestrial, and ground-nesting (Ozaki 2010). Although there is no direct evidence of predation, it is believed that juveniles and eggs of the rail are being eaten by the mongoose (Kotaka et al. 2009). Experiments with artificial nests containing eggs of Coturnix japonica have shown that eggs in the ground nests are preyed upon by the mongoose in the northern part of Okinawa Island (Kotaka and Toguchi 2020). At the time of its discovery in 1981, the distribution of the rail was limited to Yambaru (Yamashina and Mano 1981), but it is possible that the area of its distribution had already been reduced by the mongoose by this time. Ozaki et al. (2002) supposed that the area of distribution of the rail has been shrinking under the influence of the mongoose since 1985 at the latest.

There was one case in which Okinawa woodpecker feathers were detected in the digestive tract of a small Indian mongoose, suggesting that the woodpecker was predated upon by the mongoose (Kotaka et al. 2009). Woodpeckers of the genus Dendrocopos rarely forage on the ground, but Okinawa woodpecker, especially males, were reported to forage on the ground (Kotaka 2014). This habit, which developed on the island with no mammalian predators, is thought to increase their vulnerability to predation by the mongoose.

Despite the belief that Okinawa robin is not susceptible to small Indian mongoose 
Fig. 4 Response shapes for statistically significant variables, $(\mathbf{a}, \mathbf{c}, \mathbf{e})$ square root of CPUE of small Indian mongoose (Urva auropunctata), (b, d, f) hardwood forest area in the GAMM for the number of each bird species detected at each playback survey point. The partial effect shows the effect of one explanatory term on the response. The dashed lines indicate standard errors, and each tick mark at the base of the graph denotes an observation with that value. See Tables 2, 3, 4 for the parameter estimates
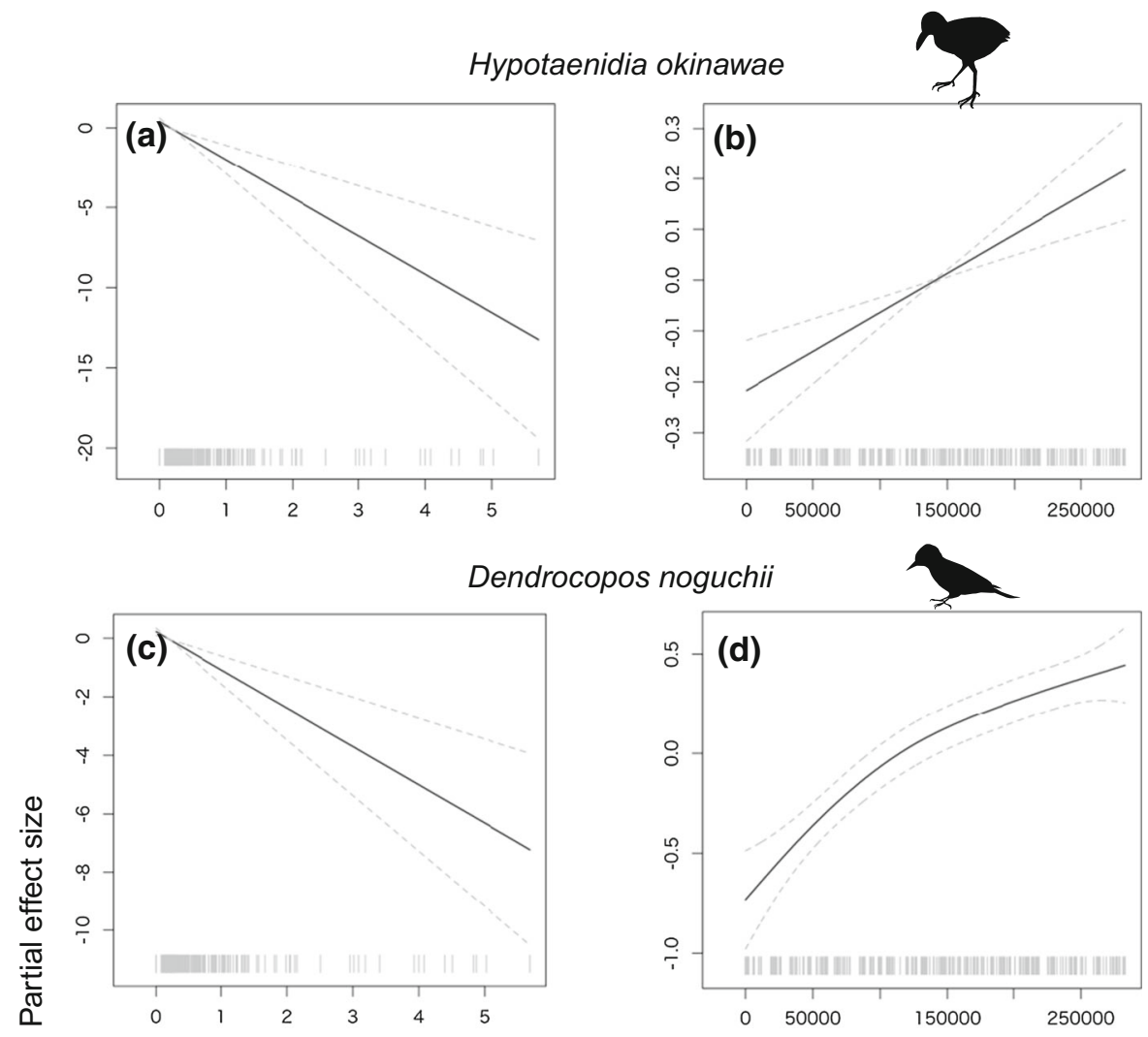

Larvivora namiyei

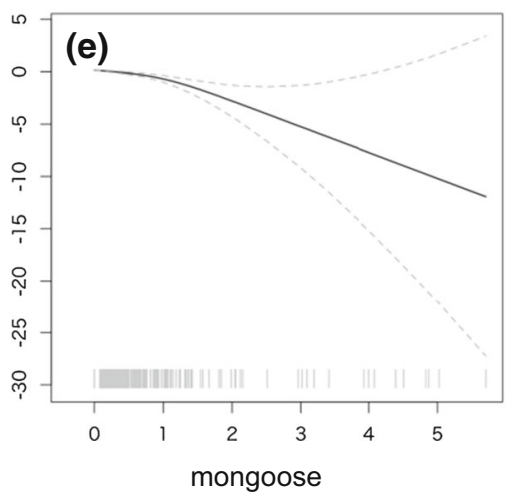

(BirdLife International 2017), this study revealed the negative impact of the mongoose on this species statistically. Because the robin frequently forages on the ground (Kotaka et al. 2009) and nests in places close to the ground, such as tree hollows, dead trees, at the foot of trees, and under fallen trees (Seki 2014), it is plausible to assume that they are preyed upon by the mongoose. On the other hand, the negative effect of the mongoose was very weak if the square root of CPUE of the mongoose was between 0 and 1 (Fig. $4 \mathrm{e}$ ). Therefore, the notion that the robin is not susceptible to the mongoose (BirdLife International 2017) is true where the density of the mongoose is comparatively low.

Effect of the forest environment

These three bird species were more abundant in areas with more hardwood forests. This suggests that these 
three bird species were dependent on large areas of forest. Moreover, it has been reported that mature forests more than 40 years old are necessary for the distribution of these three species (Department of Environmental Affairs, Okinawa Prefecture 1993). Therefore, these species were considered to be strongly affected by deforestation due to logging.

Logging peaked from the mid-1920s through the 1950s and continued until the 1980s in Kunigami village in Yambaru (Saito 2011). The area of mature forests was reduced to around $4.5 \mathrm{~km}^{2}$ in Yambaru in the late 1970s (Ogasawara and Ikehara 1977). All three bird species were likely to have been negatively affected by logging during this period.

With the increasing awareness of environmental protection and the declining demand for timber, the logging area in Yambaru has rapidly decreased since the $1970 \mathrm{~s}$, and in recent years it has been less than $0.1 \mathrm{~km}^{2}$ per year, with a total of $0.87 \mathrm{~km}^{2}$ from 1999 to 2008 (Department of Agriculture, Forestry and Fisheries 2019). Currently, the percentage of forest area in Yambaru is about $80 \%$ (Department of Agriculture, Forestry and Fisheries 2019; Shiba 2016). In 2008, $84 \%$ of the forests in Yambaru were over 40 years old and $60 \%$ were over 50 years old (Department of Agriculture, Forestry and Fisheries 2019). The recovery of forests should have a positive effect on the distribution of these three bird species.

Recovery of habitat and density of three endemic bird species

Our results indicate that the habitat of these species have been recovering since 2007. These species continued to decline until the early 2000s (Kotaka 2014; Ozaki 2014; Seki 2014), even as deforestation declined after the 1970s. Considering that $60 \%$ of the forests in Yambaru in 2008 were over 50 years old (Department of Agriculture, Forestry and Fisheries 2019), it means that more than $60 \%$ of the forests in 2000 were over 40 years old. Therefore, we can assume that the forest environment had improved considerably for these three species in the 2000s. The mongoose control program in Yambaru was therefore considered to have been effective in recovering the distribution area of these species.

Only Okinawa rail had a significant increase in the detected number of individuals at each PSP in 2016 compared with that in 2007. If we assume that the detectability was almost constant, then it can be said that as of 2016, the rail increased not only the area of its habitat but also its density. On the other hand, Okinawa woodpecker and Okinawa robin have recovered their habitat, but their density is not much different from that in 2007. This suggests that, as of 2007 , the rail may not only have decreased the area of its habitat, but may have also declined in density. Another possibility is that the dispersal ability of these three species may have an effect on the amount of habitat they occupy. The woodpecker and the robin may be able to disperse quickly when their populations increase because they can fly, whereas the rail is not able to fly. Due to its low dispersal ability, the density of the rail may temporarily increase during periods of population growth. Bird populations may be affected by factors other than the mongoose, such as weather conditions during the breeding season, and therefore longer-term studies are needed.

\section{Conclusion}

These three species were found to be negatively influenced by small Indian mongoose. It was also found that these species preferred large areas of forest. This indicates that mongoose eradication and forest protection are the key factors for the conservation of these three species. In recent years, most old-growth forests in Okinawa Island have been designated as protected forests, such as those in national parks, and large-scale logging is no longer taking place even where logging is allowed. Therefore, the eradication of the mongoose is particularly important for the conservation of these three species. Moreover, the mongoose control area needs to be expanded in order to further expand the distribution of these species in the future.

Acknowledgements We thank Asako Miyamoto, Masahiro Kudaka, Natsuko Kudaka, Katsuyoshi Oshiro, Atsushi Takashima, Ryuichiro Azuma, Atsushi Shiroma, Shoko Tokuyama, Suzunari Ishihara, Kazuhiko Saito, Masahiro Toyama, Daisuke Nanki, Sathoshi Hokama, Nature Conservation Division of Okinawa Prefectural Government, and Yambaru Ranger Office of the Ministry of the Environment of Japan for supporting our research. We thank the editors and reviewers for their comments helped us to improve the article.

Author contributions TY: formal analysis, data curation, investigation, writing - original draft, writing-review and editing. SIS: investigation, writing - review and editing. TN: 
validation, writing - review and editing. $\mathrm{KN}$ : investigation, writing-review and editing, NK: conceptualization, methodology, investigation, data curation, writing-review and editing. TY and NK: these authors contributed equally to the work.

Funding Environment Research and Technology Development Fund (JPMEERF20184004, JPMEERF2015 4003) of the Environmental Restoration and Conservation Agency of Japan; Environmental Research Fund (Assessment of human impacts on the forest biodiversity and development of mitigation techniques in Yambaru, northern part of Okinawa Island) of the Ministry of the Environment of Japan; Research Project with regard to Environmental Conservation and Resource Utilization of Forest Area in Subtropical Island Region (2008-2010) of Okinawa Prefectural Government, Japan; JSPS KAKENHI Grant Number JP19780128.

Data availability Original vegetation data were obtained from the latest vegetation surveys of the National Survey on the Natural Environment conducted by the Ministry of the Environment of Japan (Biodiversity Center of Japan 2020). Bird survey data is available in figshare (https://doi. org/10.6084/m9.figshare.14363021).

Code availability We did not use any original code. We used the package gamlss (Rigby and Stasinopoulos 2005) and the package gamlss.spatial (Bastiani et al. 2018) on R 4.0.2 (R Core Team 2020).

\section{Declarations}

Conflict of interest The authors declare that they have no conflict of interest.

Open Access This article is licensed under a Creative Commons Attribution 4.0 International License, which permits use, sharing, adaptation, distribution and reproduction in any medium or format, as long as you give appropriate credit to the original author(s) and the source, provide a link to the Creative Commons licence, and indicate if changes were made. The images or other third party material in this article are included in the article's Creative Commons licence, unless indicated otherwise in a credit line to the material. If material is not included in the article's Creative Commons licence and your intended use is not permitted by statutory regulation or exceeds the permitted use, you will need to obtain permission directly from the copyright holder. To view a copy of this licence, visit http://creativecommons.org/licenses/by/4.0/.

\section{References}

Abe S (1994) Current status of introduced mongoose on Okinawa Island. Chirimos 5:34-43 (in Japanese)

Baldwin PH, Schwartz CW, Schwartz ER (1952) Life history and economic status of the mongoose in Hawaii. J Mammal 33:335-356. https://doi.org/10.2307/1375771
Barun A, Simberloff D, Budinski I (2010) Impact of the small Indian mongoose on native amphibians and reptiles of the Adriatic islands, Croatia. Anim Conserv 13:549-555. https://doi.org/10.1111/j.1469-1795.2010.00374.x

Barun A, Hanson C, Campbell K et al (2011) A review of small Indian mongoose management and eradications on islands. In: Veitch CR, Clout MN, Towns DR (eds) Island invasives: eradication and management. IUCN, Gland, Switzerland, pp 17-25

Bastiani FD, Stasinopoulos M, Rigby R (2018) gamlss.spatial: Spatial Terms in Generalized Additive Models for Location Scale and Shape Models. R package version 2.0.0. https://CRAN.R-project.org/package=gamlss.spatial

Bibby C, Jones M, Marsden S (2000) Bird surveys. BirdLife International, Cambridge

Biodiversity Center of Japan (2020) Vegetation Survey (1/ 25,000) List by Prefecture. http://gis.biodic.go.jp/webgis/ sc-025.html?kind=vg67 Accessed 3 September 2020 (In Japanese)

BirdLife International (2016) Hypotaenidia okinawae. IUCN Red List Threat Species. https://doi.org/10.2305/IUCN. UK.2016-3.RLTS.T22692412A93352408.en

BirdLife International (2017) Larvivora namiyei. IUCN Red List Threat Species. https://doi.org/10.2305/IUCN.UK. 2017-1.RLTS.T103767739A111960458.en

BirdLife International (2018) Dendrocopos noguchii (amended version of 2016 assessment). The IUCN Red List Threat Species. https://doi.org/10.2305/IUCN.UK.2018-2.RLTS. T22681531A125513230.en

Courchamp F, Chapuis JL, Pascal M (2003) Mammal invaders on islands: impact, control and control impact. Biol Rev Camb Philos Soc 78:347-383. https://doi.org/10.1017/ s1464793102006061

Department of Environmental Affairs, Okinawa Prefecture (1993) Habitat surveys for endangered birds VI. Okinawa Prefectural Government, Naha (in Japanese)

Department of Agriculture, Forestry and Fisheries (2019) Promotion of Yambaru-style forestry (revised version). Okinawa prefecture Web. https://www.pref.okinawa.jp/site/ norin/shinrin/kikaku/documents/sesakuhoushin

r0109syuusei.pdf Accessed 3 September 2020 (in Japanese)

Horst GR, Hoagland DB, Kilpatrick CW (2001) The mongoose in the West Indies: the biogeography and population biology of an introduced species. In: Woods CA, Sergile FE (eds) Biogeography of the West Indies: Patterns and Perspectives, 2nd edn. CRC Press, New York, pp 435-450

Japan Map Centre (1998) Numerical map users guide 2nd version. Japan Map Centre, Tokyo (in Japanese)

Japan Meteorological Agency (2020) Historical weather data search. http://www.data.jma.go.jp/obd/stats/etrn/index. php Accessed 3 September 2020 (in Japanese)

Kishida K (1931) Professor Watase and the import of mongooses. Zoological Mag 43:70-78

Kotaka N (2014) Okinawa woodpecker. In: Ministry of the Environment (ed.) Red data book 2014 vol. 2 Aves. GYOSEI Corpration, Tokyo, pp 64-65 (In Japanese with English abstract)

Kotaka N, Toguchi Y (2020) Comparing artificial ground nest predation pressure and predator composition in mongoose infested and un-infested area of northern part of Okinawa 
Island. Jpn J Ornithol 69:19-30. https://doi.org/10.3838/ jjo.69.19 (In Japanese with English abstract)

Kotaka N, Kudaka M, Takehara K et al (2009) Ground use pattern by forest animals and vulnerability toward invasion by Herpestes javanicus into Yambaru, Northern Okinawa Island, southern Japan. Jpn J Ornithol 58:28-45. https:// doi.org/10.3838/jjo.58.28 (In Japanese with English abstract)

Lowe S, Browne M, Boudjelas S et al (2000) 100 of the world's worst invasive alien species: a selection from the global invasive species database. Invasive Species Specialist Group Auckland, New Zealand

Ministry of the Environment Government of Japan (2019) Red list 2019, Ministry of the Environment. http://www.env.go. jp/press/files/jp/110615.pdf Accessed 2 September 2020 (in Japanese)

Ministry of the Environment, Okinawa Prefecture (2019) 5-31 Phase 3 Mongoose Control Plan for the Northern Part of Okinawa Island (JFY2017 to 2026). Nomination of Amami-Oshima Island, Tokunoshima Island, Northern Part of Okinawa Island, and Iriomote Island for Inscription on the World Heritage List - Annexes - https://www.env. go.jp/press/files/jp/110738.pdf Accessed 2 September 2020

Mizuta T, Takashi M, Torikai H et al (2017) Song-count surveys and population estimates reveal the recovery of the endangered Amami Thrush Zoothera dauma major, which is endemic to Amami-Oshima Island in south-western Japan. Bird Conserv Int 27:470-482. https://doi.org/10. 1017/s095927091600023x

Nagelkerke NJ (1991) A note on a general definition of the coefficient of determination. Biometrika 78:691-692. https://doi.org/10.1093/biomet/78.3.691

Ogasawara K, Ikehara S (1977) Ecological and behavioral observations of Okinawa Woodpecker Sapheopipo noguchii, with notes on conservation. J Yamashina Inst Ornithol 9:143-158. https://doi.org/10.3312/jyio1952.9.143

Ogawa M (1905) Notes on Mr. Alan Owston's collection of birds from the Islands lying between Kiushu and Formosa. Annot Zool Jpn 5:175-232

Ozaki K (2010) Conservation biology of Okinawa Rail Gallirallus okinawae. Ph.D. Thesis Toho Univ. (in Japanese)

Ozaki K (2014) Okinawa rail. In: Ministry of the Environment (ed.) Red data book 2014 vol. 2 Aves. GYOSEI Corpration, Tokyo, pp 44-45 (in Japanese with English abstract)

Ozaki K, Baba T, Komeda S et al (2002) The declining distribution of the Okinawa Rail Gallirallus okinawae. J Yamashina Inst Ornithol 34:136-144. https://doi.org/10. 3312/jyio1952.34.136 (in Japanese with English abstract)
QGIS Development Team (2020) QGIS Geographic Information System. Open Source Geospatial Foundation Project. http://qgis.osgeo.org

R Core Team (2020) R: A language and environment for statistical computing. R Foundation for Statistical Computing, Vienna

Rigby RA, Stasinopoulos DM (2005) Generalized additive models for location, scale and shape. J R Stat Soc Ser C Appl Stat 54:507-554. https://doi.org/10.1111/j.14679876.2005.00510.x

Roy S, Jones C, Harris S (2002) An ecological basis for control of the mongoose Herpestes javanicus in Mauritius: is eradication possible. In: Veitch $\mathrm{CR}$ and Clout MN (eds) Turning the tide: the eradication of invasive species. IUCN SSC Invasive Species Specialist Group. IUCN, Gland, Switzerland and Cambridge, UK., pp 266-273

Saito K (2011) Forest age distribution in Kunigami-village, Okinawa, based on forest register data. Environ Info Sci 25:245-250. https://doi.org/10.11492/ceispapers.ceis25.0_ 245 (in Japanese with English abstract)

Seki SI (2014) Ryukyu robin. In: Ministry of the Environment (ed.) Red data book 2014 vol. 2 Aves. GYOSEI Corpration, Tokyo, pp 122-123 (in Japanese with English abstract)

Shiba M (2016) Historical evolution and future prospects of Okinawa's forestry: a major paradigm shift for sustainable forest management. Sci Bull Fac Agri Univ Ryukyus 63:51-60 (in Japanese with English abstract)

Short LL (1973) Habits, relationships, and conservation of the Okinawa woodpecker. Wilson Bull 85:5-20

Watari Y, Takatsuki S, Miyashita T (2007) Effects of exotic mongoose (Herpestes javanicus) on the native fauna of Amami-Oshima Island, southern Japan, estimated by distribution patterns along the historical gradient of mongoose invasion. Biol Invasions 10:7-17. https://doi.org/10.1007/ s10530-007-9100-6

Yamada F, Sugimura K (2004) Negative impact of an invasive small Indian mongoose Herpestes javanicus on native wildlife species and evaluation of a control project in Amami-Ohshima and Okinawa Islands, Japan. Glob Environ Res 8:117-124

Yamashina Y, Mano T (1981) A New Species of Rail from Okinawa Island. J Yamashina Inst Ornithol 13:147-152. https://doi.org/10.3312/jyio1952.13.147

Publisher's Note Springer Nature remains neutral with regard to jurisdictional claims in published maps and institutional affiliations. 